\title{
Penilaian Persepsi Aspek Lingkungan Pada Bandara Internasional Sultan Iskandar Muda Provinsi Aceh dengan Method Of Successive Interval (MSI)
}

\author{
Cut Rizki Noor Annisa ${ }^{1}$ Buraida $^{2}$ Febriyanti Maulina ${ }^{3}$ \\ ${ }^{1}$ Mahasiswa, Jurusan Teknik Sipil, Universitas Syiah Kuala, Banda Aceh 23111, Indonesia \\ 2,3 Jurusan Teknik Sipil, Universitas Syiah Kuala, Banda Aceh 23111, Indonesia \\ Email: cutrizki96@gmail.com
}

\begin{abstract}
The high number of aircraft in Indonesia, it should be noted to the Government about the airport. One of the efforts that can be done by applying the concept of eco airport. Currently, Sultan Iskandar Muda International Airport, not included in the airport that has applied eco airport concept. Therefore, it is necessary to review assessment of the application of Eco Airport concept. Based on the background, the problem formulation in this research is how much perception and application of the concept of eco airport at the airport in Aceh province. Research location at Terminal Building in Sultan Iskandar Muda International Airport Aceh with a total of 120 respondents. This research uses primary data in the form of questionnaire and secondary data in the form of data obtained from the results of libraries, literature studies and journals. The results of this study came the average value of the visitor respondent's perception of eco airport concept application is $56.91 \%$ which is categorized good enough. The average value of the airport employee respondent's perception is $52.85 \%$ which is categorized quite well. The benefit of this research to the airport manager is to be able to prepare the concept of eco airport at the airport and provide information for readers about eco airport.
\end{abstract}

Keyword: Eco Airport, Sultan Iskandar Muda International Airport, Terminal Building

\begin{abstract}
Abstrak
Tingginya penggunaan pesawat terbang di Indonesia, mengharuskanpemerintah lebih memperhatikan mengenai bandara. Upaya yang dapat dilakukan dengan menerapkan konsep bandara ramah lingkungan (eco airport). Saat ini,Bandara Internasional Sultan Iskandar Muda belum termasuk dalam bandara yang telah menerapkan konsep eco airport. Oleh karena itu, perlu dilakukannya tinjauan penilaian terhadap penerapan konsep eco airport. Rumusan masalah dalam penelitian ini yaitu seberapa besar persepsi dan penerapan konsep eco airport pada Bandara Internasional Sultan Iskandar Muda. Penelitian dilakukan di Gedung Terminal Penumpang Bandara Internasional Sultan Iskandar Muda Aceh dengan jumlah responden sebanyak 120 orang. Penelitian ini menggunakan data primer berupa kuisioner dan data sekunder berupa data yang diperoleh dari hasil penelitian kepustakaan, kajian-kajian literatur dan jurnal-jurnal. Hasil dari penelitian ini didapatkan nilai rata-rata persepsi responden pengunjung terhadap penerapan konsep eco airport sebesar $56,91 \%$ yang dikategorikan cukup, dan persepsi responden pegawai bandara sebesar 52,85\% yang dikategorikan cukup. Manfaat dari penelitian ini kepada pengelola bandara yaitu sebagai informasi agar dapat diterapkannya konsep eco airport yang sebaik-baiknya pada bandara dan memberikan pula informasi bagi pembaca mengenai eco airport.
\end{abstract}

Kata Kunci : Eco Airport, Bandara Internasional Sultan Iskandar Muda, Gedung Terminal

\section{Pendahuluan}

Tingginya angka penggunaan pesawat terbang di Indonesia, mengharuskanpemerintah lebih memerhatikan mengenai bandara. Perencanaan dan pengembangan pembangunan bandara ke depan harus memperhatikan lingkungan sehingga bandara dapat berfungsi secara efektif dan efisien tidak hanya dari aspek teknis saja tapi juga dari segi sosial kemasyarakatan, ekonomi, dan lingkungan. Salah satu upaya yang dapat dilakukan dengan cara menerapkan konsep bandara ramah lingkungan (eco airport).

Menurut Rachman[1] Konsep Bandara Ramah lingkungan (Eco airport) merupakan rancangan dimana bandara direncanakan, dikembangkan, dan dioperasikan dengan tujuan menciptakan sarana dan prasarana yang ramah lingkungan. Konsep eco airport ini seiring dengan rencana lingkungan hidup dunia, yang berfokus pada $A S E A N$, sebagai percontohan adalah ASEAN-Japan Eco Airport Guidline, yang juga searah dengan Undang-undang Presiden Republik Indonesia No. 1 Tahun 2009 tentang kewajiban bagi seluruh bandara di Indonesia untuk melaksanakan eco airport dengan memperhatikan faktorfaktor utama lingkungan seperti pencemaran udara, penghijauan, penggunaan air bersih, penghematan energi listrik dan pengelolaan limbah.

Informasi awal dari wawancara dengan pihak pengelola bandara (bagian infrastruktur) mengatakan bahwa eco airport menurut Peraturan Direktural Jenderal Perhubungan Udara Nomor: SKEP/124/VI/2009 belum diterapkan pada Bandara Internasional Sultan Iskandar Muda Provinsi Aceh. Namun, pengelolaan lingkungan dan pemantauan lingkungan yang mengacu pada Keputusan Menteri Lingkungan Hidup No. 45 Tahun 2005 Tentang 
Pedoman Penyusunan Laporan Pelaksanaan RKL - RPL dan beberapa dasar hukum atau peraturan terkait lainnya rutin di lakukan dan di laporkan ke pihak Dinas Lingkungan Hidup. Kondisi bandara saat ini masih banyak yang perlu ditingkatkan lagi seperti area dasar hijau yang terdapat di bandara masih perlu diperluas dan tanamantanaman juga perlu ditambahkan, penghematan energi serta pengolahan limbah pada bandara juga masih perlu di perhatikan. Oleh karena itu, Bandara Internasional Sultan Iskandar Muda perlu dilakukannya tinjauan penilaian terhadap penerapan konsep bandara ramah lingkungan (eco airport) berdasarkan persepsi pengunjung dan pegawai bandara.

Adapun tujuan dalam penelitian ini adalah untuk mengetahui nilai persepsi responden terhadap konsep eco airport dan mengetahui nilai penerapan konsep eco airport pada Bandara Internasional Sultan Iskandar Muda di Provinsi Aceh.

\section{Tinjauan Kepustakaan}

\subsection{Bandar Udara (Bandara)}

Bandar udara atau bandara adalah lapangan udara, termasuk segala bangunan dan peralatan yang merupakan kelengkapan minimal untuk menjamin tersedianya fasilitas bagi angkutan udara untuk masyarakat.

Bandara berfungsi sebagai suatu tempat dengan segala perlengkapan beserta gedungnya, dipakai untuk pemberangkatan, pendaratan dan pelayanan bagi pesawat terbang dengan segala muatannya, berupa penumpang dan barang. Artinya, bandara merupakan tempat perpindahan dari sub sistem angkutan udara ke udara, udara ke darat atau udara ke air.

\subsection{Terminal Penumpang}

Terminal penumpang adalah bangunan yang menjadi penghubung sistem transportasi darat dan sistem transportasi udara yang menampung kegiatan-kegiatan transisi antara akses dari darat ke pesawat udara atau sebaliknya; pemrosesan penumpang datang, berangkat maupun transit dan transfer serta pemindahan penumpang dan bagasi dari dan ke pesawat udara. Terminal penumpang harus mampu menampung kegiatan operasional, administrasi dan komersial serta harus memenuhi persyaratan keamanan dan keselamatan operasi penerbangan, disamping persyaratan lain yang berkaitan dengan masalah bangunan.

Fungsi terminal adalah untuk penyediaan fasilitas masuk dan keluar objek-objek yang akan diangkut, penumpang atau barang, menuju dan dari system. Pada sistem transport kendaraan, tujuan utama dari terminal adalah untuk membongkar dan memuat kendaraan atau peti kemas. Terminal ditempatkan pada lokasi dimana lalu lintas memasuki dan meninggalkan sistem. Sedangkan fungsi utama terminal pada Bandar udara adalah untuk menghubungkan akses darat dan hubungan di udara.

\subsection{Bandara Sultan Iskandar Muda}

Bandar Udara Internasional Sultan Iskandar Muda, dikenal juga dengan Bandara Sultan Iskandar Muda (IATA:BTJ, ICAO:WITT) adalah sebuah Bandar udara yang melayani Kota Banda Aceh dan sekitarnya, yang terletak di wilayah Kecamatan Blang Bintang, Aceh Besar, Provinsi Aceh. Bandara ini dibangun oleh Pemerintah Jepang pada tahun 1943.Pada saat ini, Bandara Sultan Iskandar Muda dikelola oleh PT Angkasa Pura II, untuk melayani rute domestik dan internasional.

\subsection{Pengertian Eco Airport}

Menurut Adisasmita[2] Eco airport adalah kajian tentang bandara yang memperhatikan aspek-aspek komponen lingkungan hidup. Konsep eco airport adalah membuat/memperkuat kebijakan dan pengawasan yang kritis terhadap peningkatan operasi dan kualitas lingkungan bandar udara. Kajian-kajian secara mendalam terhadap pengelolaan lingkungan menjadi pijakan dalan memberikan rekomendasi. Perbedaan parameter yang menjadi ukuran dampak pencemaran di setiap Negara tidaklah sama. Namun apapun terminologinya semua berujung pada pencegahan pencemaran (Prevention Pollution) di bandar udara. Penerapan eco airport di bandar udara dapat dilakukan dengan perubahan dan memperbaiki teknologi dibidang penerbangan sipil dan pengelola kebandar udaraan yang berbasis lingkungan.

\subsection{Peraturan Direktur Jenderal Perhubungan Udara Nomor : SKEP/124/VI/2009 Tentang Pedoman Pelaksanaan Bandar Udara Ramah Lingkungan (Eco Airport)}

Dalam rangka mewujudkan tujuan Bandar udara ramah lingkungan (eco airport), administrator atau penyelenggara Bandar udara wajib melakukan kegiatan pengelolaan dan pemantauan lingkungan hidup di Bandar udara dan sekitarnya bagi Bandar udara internasional dan badar udara pengumpul dengan skala pelayanan primer. Pengelolaan dan pemantauan lingkungan hidup terdiri atas komponen:

a. Kualitas Udara (Air Quality)-Atmosphere;

b. Energy (Energy);

c. Kebisingan/Getaran (Noise/Vibration);

d. Air (Water);

e. Pencemaran Tanah (Soil);

f. Limbah (Waste);

g. Lingkungan Alamiah (Natural Enviroment)Flora/Fauna; Dan

h. Lain-Lainnya (Others) - Social Economic/Culture/Public Health.

\subsection{Penentuan Jumlah Sampel}

Menurut Sevilla, dkk[3] penentuan jumlah sampel minimum dilakukan dengan mengunakan rumus Slovin dengan toleransi kesalahan analisa yang diizinkan adalah $10 \%$. Rumus yang digunakan adalah sebagai berikut:

$\mathrm{n}=\frac{N}{1+\left(N \cdot e^{2}\right)}$ 
Keterangan :

$\mathrm{n}=$ Jumlah Sampel

$\mathrm{N}=$ Jumlah Populasi

$\mathrm{e}=$ Persentase toleransi ketidaktelitian/ yang masih dapat ditolerin

\subsection{Skala Likert}

Riduwan[4] menjelaskan Skala Likert adalah skala yang dapat dipergunakan untuk mengukur sikap, pendapat, dan persepsi seseorang atau sekelompok orang tentang suatu gejala atau fenomena pendidikan. Untuk mendapatkan jawaban harus dibuat instrumen (kuisioner) yang dihubungkan dengan bentuk pernyataan atau dukungan sikap yang diungkapkan dengan suatu kata-kata atau indikator tertentu.Sewaktu menanggapi pertanyaan dalam skala Likert, responden menentukan tingkat persetujuan mereka terhadap suatu pernyataan dengan memilih salah satu dari pilihan yang tersedia, yaitu:

$$
\begin{aligned}
& 5=\text { Sangat Setuju/Sangat Baik } \\
& 4=\text { Setuju/Baik } \\
& 3=\text { Cukup Setuju/Cukup Baik } \\
& 2=\text { Kurang Setuju/Kurang Baik } \\
& 1=\text { Sangat Tidak Setuju/Sangat Tidak Baik }
\end{aligned}
$$

\subsection{Distribusi Frekuensi}

Distribusi frekuensi adalah pengelompokan data atau tabel ringkasan data yang menunjukkan banyaknya objek pada setiap kelas yang ada. Perhitungan frekuensi kumulatif menggunakan rumus sederhana sebagai berikut:

$$
F_{\text {komulatif }}=\frac{F_{\text {kumabsolut }}}{n} \times 100 \%
$$

Dimana :

$\mathrm{n}=$ jumlah subjek

$F_{\text {kumabsolut }}=$ data yang diperoleh per item pertanyaan

$F_{\text {komulatif }}=$ persentase jawaban responden

\subsection{Mean (Rata-Rata)}

Menurut Sugiyono[5] mean atau rata-rata adalah teknik penjelasan kelompok didasarkan atas nilai rata-rata dari kelompok tersebut. Mean suatu data juga merupakan statistik karena mampu menggambarkan bahwa data tersebut berada pada kisaran mean data tersebut.

$$
\bar{x}=\frac{\sum X_{i}}{n}
$$

Dimana :

$$
\begin{array}{ll}
\bar{x} & =\text { rata-rata } \\
X_{i} & =\text { jumlah keseluruhan nilai data } \\
n & =\text { jumlah seluruh frekuensi }
\end{array}
$$

\subsection{Method of Successive Interval (MSI)}

Analisis statistik parametrik (statistik yang bergantung pada distribusi tertentu dan yang menetapkan adanya syarat-syarat tertentu tentang parameter populasi seperti pengujian hipotesis dan penaksiran parameter) memerlukan terpenuhinya persyaratan bahwa skala pengukuran minimal interval, sedangkan data penelitian diperoleh data yang memberikan skala pengukuran ordinal, agar analisis tersebut dapat dilanjutkan maka skala pengukuran ordinal harus dinaikkan (ditransformasikan) kedalam skala interval dengan menggunakan Methode of Successive Interval (MSI).

Menurut Sedarmayanti[6] Methode of Successive Interval adalah sebuah metode penskalaan untuk menaikkan skala pengukuran ordinal keskala pengukuran interval. Langkah-langkah transformasi data ordinal ke data interval yaitu:

1. Perhatikan nilai jawaban dari setiap pertanyaan dalam kuesioner;

2. Untuk setiap pertanyaan tersebut, lakukan perhitungan ada berapa responden yang menjawab skor 1, 2, 3, 4, 5 = frekuensi (f);

3. Setiap frekuensi dibagi dengan banyaknya $n$ responden dan hasilnya $=$ proporsi $(\mathrm{p})$;

4. Kemudian hitung proporsi kumulatifnya (pk);

5. Dengan menggunakan tabel normal, dihitung nilai distribusi normal (Z) untuk setiap proporsi kumulatif yang diperoleh;

$$
\delta(Z)=\frac{1}{\sqrt{2 \pi}} e^{\left(-\frac{Z^{2}}{2}\right)},-\infty<Z<+\infty
$$

6. Tentukan nilai densitas normal ( fd ) yang sesuai dengan nilai $\mathrm{Z}$;

7. Tentukan nilai interval (scale value) untuk setiap skor jawaban;

8. Sesuaikan nilai skala ordinal ke interval, yaitu Skala Value (SV) yang nilainya terkecil (harga negatif yang terbesar) diubah menjadi sama dengan jawaban responden yang terkecil melalui transformasi berikut ini:

Transformed Scale Value $: \mathrm{SV}=-\{$ Min data Min SV \}

\subsection{Analisis Deskriptif}

Menurut Sugiono[7] analisis deskriptif adalah analisis yang berfungsi untuk mendeskripsikan atau memberi gambaran terhadap objek yang diteliti melalui data sampel atau populasi sebagaimana adanya. Data dari angket dalam penelitian ini merupakan data kuantitatif yang akan dianalisis secara deskriptif persentase. Rumus yang digunakan adalah :

$$
D P=\frac{n}{N} \times 100 \%
$$

Keterangan:

$D P=$ Deskriptif Persentase $(\%)$

$n=$ Skor empirik (Skor yang diperoleh)

$N=$ Skor maksimal item pertanyaan

Untuk mengetahui tingkat kriteria data, selanjutnya hasil yang diperoleh (dalam \%) dengan analisis deskriptif persentase dikonsultasikan dengan tabel kriteria. 
Tabel 1 Kriteria Interpretasi Skor

\begin{tabular}{ccl} 
No & Presentase Skor & Kualifikasi \\
\hline 1 & Angka $80 \%-100 \%$ & Sangat Tinggi/Sangat Baik \\
\hline 2 & Angka $60 \%-79,99 \%$ & Tinggi/Baik \\
\hline 3 & Angka $40 \%-59,99 \%$ & Cukup/Cukup Baik \\
\hline 4 & Angka 20\% - 39,99\% & Rendah/Kurang Baik \\
\hline 5 & Angka 0\% - 19,99\% & Sangat Rendah/Sangat Tidak Baik \\
Sumber : Riduwan[4] &
\end{tabular}

\section{Metodologi Penelitian}

\subsection{Lokasi dan Objek Penelitian}

Penelitian ini bertempat di Jl. Bandara Sultan Iskandar Muda, Blang Bintang, Cot Mancang, Kuta Baro, Kabupaten Aceh Besar. Sedangkan objek penelitian ini adalah Bandar Udara Internasional Sultan Iskandar Muda Provinsi Aceh

\subsection{Sumber Data}

Data yang dikumpulkan dalam penelitian ini ada dua jenis data yaitu data primer dan data sekunder. Data primer adalah data yang diperoleh dari hasil wawancara dan pengisisan kuisioner yang disebarkan kepada para responden secara langsungsedangkan data sekunder pada penelitian ini antara lain, Laporan Pelaksanaan Rencana Pengelolaan Lingkungan (RPL) dan Rencana Kegiatan Lingkungan (RKL) Bandara Internasional Sultan Iskandar Muda semester 1 Januari-Juni 2018, peta lokasi penelitian, dan data jumlah pengunjung dan pegawai Bandara Internasional Sultan Iskandar Muda.

\subsection{Teknik Pengumpulan Data}

Data dikumpulkan dengan metode wawancara, dengan pengisian kuesionerdisebarkan kepada para responden secara langsung dari lokasi penelitian atau pengamatan di lapangan, untuk lokasi penyebaran kuisioner pada responden pengunjung bandara dilakukan di Ruang Tunggu Domestik Bandara Internasional Sultan Iskandar Muda dan untuk penyebaran kuisioner pada responden pegawai bandara dilakukan di Kantor Angkasa Pura II Bandara Internasional Sultan Iskandar Muda. Untuk pengisian kuisioner, peneliti membimbing dan menjelaskan cara pengisian kuisioner agar tidak terjadi penyimpangan dari lingkup penelitian dan pengumpulan data kuisioner yang dilakukan langsung pada hari tersebut.Kuesioner dirancang dalam dua bagian, yaitu kuisioner A merupakan karakteristik dan informasi umum responden, data karakteristik responden yang ditujukan untuk pengunjung bandara yaitu, nama, pekerjaan, pendidikan, jenis kelamin, umur, penerbangan yang digunakan, dan tujuan ke bandara. Data karakteristik responden yang ditujukan untuk pegawai bandara yaitu, nama, jabatan, pendidikan, jenis kelamin, umur, dan berapa tahun pengalaman kerja dibandara. Responden ditentukan menggunakan rumus Slovin (persamaan 2.1). Jumlah pengunjung bandara pada pukul 11.00-17.00 WIB sebanyak 1000 orang dan pegawai yang bertugas di bandara sebanyak 40 orang, setelah dilakukan perhitungan didapatkan jumlah responden sebanyak 120 orang, dimana responden pengunjung bandara sebanyak 91 orang dan responden pegawai bandara sebanyak 29 orang. Sedangkan untuk informasi umum berisi pertanyaan-pertanyaan tentang kebiasaan responden terhadap Bandara Sultan Iskandar Muda. Kuisioner B merupakan Penilaian responden terhadap Bandara Sultan Iskandar Muda, kuisioner ini berisi beberapa pernyataan mengenai Bandara Sultan Iskandar Muda, yang akan dijawab langsung oleh responden pengunjung bandara dengan dibantu peneliti dan akan diukur oleh peneliti dengan menggunakan pengukuran skala Likert. Kusioner B untuk responden pegawai bandara berbeda dengan kuisioner B untuk responden pengunjung bandara, namun untuk uraian pernyataan sikapnya sama.

\subsection{Teknik Analisis Data}

Data-data yang telah dikumpulkan kemudian diolah dengan menggunakan metode pengolahan data dengan langkah-langkah sebagai berikut:

1. Karakteristik responden diolah dengan persamaan distribusi frekuensi untuk mendapatkan deskripsi persentase hasil jawaban responden. Hasil dari deskripsi persentase jawaban responden akan ditampilkan dalam bentuk tabel.

2. Selanjutnya data hasil kuisioner akan dilanjutkan dengan dilakukannya analisis menggunakan metode mean untuk melihat rata-rata persepsi dan penerapan konsep eco airport pada Bandara Internasional Sultan Iskandar Muda . Pengujian mean dapat dilihat pada persamaan (2.2).

3. Setelah semua pengujian dilakukan, maka data yang didapat akan diolah menggunakan analisa deskriptif, dan hasil dari analisa deskriptif dalam bentuk persentase. Pengujian deskriptif dapat dilihat pada persamaan (2.3)

\section{Hasil dan Pembahasan}

\subsection{Karakteristik Responden}

Karakteristik dari 120 responden tersebut ditampilkan dalam bentuk tabel. Dapat dilihat pada tabel dibawah ini :

Tabel 2 Karakteristik Responden Pengunjung Bandara

\begin{tabular}{clcc} 
No. & \multicolumn{1}{c}{ Demografi } & Frekuensi & Persentase $(\%)$ \\
\hline 1 & Umur & & \\
\cline { 2 - 4 } & $<20$ Tahun & 5 & 5,49 \\
\cline { 2 - 4 } & 20-30 Tahun & 33 & 36,26 \\
\cline { 2 - 4 } 2 & $>$ 30 Tahun & 53 & 58,24 \\
\cline { 2 - 4 } & Jenis Kelamin & & \\
\cline { 2 - 4 } & Laki-laki & 63 & 69,23 \\
\cline { 2 - 4 } 3 & Perempuan & 28 & 30,77 \\
\cline { 2 - 4 } & Pendidikan Terakhir & & \\
\cline { 2 - 4 } & SD & 0 & 0 \\
\cline { 2 - 4 } & SMP & 0 & 14,29 \\
\cline { 2 - 4 } & SMA & 10 & 52,75 \\
\cline { 2 - 4 } & Diploma & 48 & 21,98 \\
\cline { 2 - 4 } & Sarjana (S1) & 20 & \\
\cline { 2 - 4 } & Pasca Sarjana & & \\
& & &
\end{tabular}




\begin{tabular}{|c|c|c|c|}
\hline \multirow[t]{5}{*}{4} & \multicolumn{3}{|l|}{ Pekerjaan } \\
\hline & PNS & 18 & 19,78 \\
\hline & Wirausaha & 13 & 14,29 \\
\hline & Swasta & 35 & 38,46 \\
\hline & Lainnya & 25 & 27,47 \\
\hline \multirow[t]{7}{*}{5} & \multicolumn{3}{|c|}{ Penerbangan yang Digunakan } \\
\hline & Batik Air & 8 & 8,79 \\
\hline & Lion Air & 39 & 42,86 \\
\hline & Air Asia & 0 & 0 \\
\hline & Garuda Indonesia & 20 & 21,98 \\
\hline & Malindo Air & 0 & 0 \\
\hline & Lainnya & 24 & 26,37 \\
\hline \multirow[t]{5}{*}{6} & \multicolumn{3}{|l|}{ Tujuan Ke Bandara } \\
\hline & Melakukan Perjalanan & 91 & 100 \\
\hline & Menjemput & 0 & 0 \\
\hline & Rekreasi & 0 & 0 \\
\hline & Lainnya & 0 & 0 \\
\hline \multirow[t]{4}{*}{7} & \multicolumn{3}{|c|}{ Seberapa Sering Ke Bandara } \\
\hline & $<5$ Kali & 53 & 58,24 \\
\hline & 5-10 Kali & 18 & 19,78 \\
\hline & $>10 \mathrm{Kali}$ & 20 & 21,98 \\
\hline \multirow[t]{3}{*}{8} & \multicolumn{3}{|c|}{ Seberapa Sering Gunakan Pesawat } \\
\hline & Sering & 50 & 54,95 \\
\hline & Tidak Sering & 41 & 45,05 \\
\hline \multirow[t]{3}{*}{9} & \multicolumn{3}{|c|}{ Alami Penundaan Pesawat } \\
\hline & $\mathrm{Ya}$ & 60 & 65,93 \\
\hline & Tidak & 31 & 34,07 \\
\hline \multirow[t]{3}{*}{10} & \multicolumn{3}{|c|}{ Proses Pengambilan Bagasi } \\
\hline & Lama & 8 & 8,79 \\
\hline & Tidak Lama & 83 & 91,21 \\
\hline \multirow[t]{3}{*}{11} & \multicolumn{3}{|c|}{ Transportasi yang Digunakan } \\
\hline & Kendaraan Pribadi & 49 & 53,85 \\
\hline & Transportasi Umum & 42 & 46,15 \\
\hline
\end{tabular}

Tabel 3 Karakteristik Responden Pegawai Bandara

\begin{tabular}{|c|c|c|c|}
\hline No. & Demografi & Frekuensi & Persentase \\
\hline \multirow[t]{4}{*}{1} & Umur & & \\
\hline & $<20$ tahun & 0 & 0 \\
\hline & 20-30 tahun & 7 & 24,138 \\
\hline & $>30$ tahun & 22 & 75,862 \\
\hline \multirow[t]{3}{*}{2} & Jenis Kelamin & & \\
\hline & Laki-laki & 22 & 75,862 \\
\hline & Perempuan & 7 & 24,138 \\
\hline \multirow[t]{7}{*}{3} & Pendidikan Terakhir & & \\
\hline & SD & 0 & 0 \\
\hline & SMP & 0 & 0 \\
\hline & SMA & 2 & 6,897 \\
\hline & Diploma & 5 & 17,241 \\
\hline & Sarjana (S1) & 21 & 72,414 \\
\hline & Pasca Sarjana & 1 & 3,448 \\
\hline \multirow[t]{4}{*}{4} & Lama Bekerja & & \\
\hline & $<5$ Tahun & 5 & 17,241 \\
\hline & 5-10 Tahun & 9 & 31,034 \\
\hline & $>10$ Tahun & 15 & 51,724 \\
\hline \multirow[t]{3}{*}{5} & Transportasi yang Di & nakan & \\
\hline & Kendaraan Pribadi & 28 & 96,552 \\
\hline & Transportasi Umum & 1 & 3,448 \\
\hline \multirow[t]{3}{*}{6} & Pernah Mengikuti Pe & tihan & \\
\hline & Pernah & 29 & 100 \\
\hline & Tidak Pernah & 0 & 0 \\
\hline
\end{tabular}

4.2 Persepsi Responden Terhadap Penerapan Konsep Bandara Ramah Lingkungan Pada Bandara Internasional Sultan Iskandar Muda

Setelah melakukan pengumpulan data, maka perlu dilakukan perubahan skala data dari data ordinal menjadi data interval agar dapat dirata-ratakan dan dianalisis secara deskriptif. Setelah itu akan dilakukan analisa deskriptif yang bertujuan untuk mendeskripsikan persepsi responden tentang penerapan konsep bandara ramah lingkungan pada Bandara Internasional Sultan Iskandar Muda.

Tabel 4 Hasil Analisa Deskriptif Persepsi Responden Pengunjung Terhadap Penerapan Konsep Bandara Ramah Lingkungan Pada Bandara Internasional Sultan Iskandar Muda

\begin{tabular}{|c|c|c|c|c|}
\hline $\begin{array}{l}\mathrm{N} \\
\mathrm{O}\end{array}$ & Pernyataan & $\begin{array}{c}\text { Mea } \\
\mathrm{n}\end{array}$ & $\begin{array}{c}\text { Persentas } \\
\mathrm{e}\end{array}$ & Keterangan \\
\hline 1 & $\begin{array}{l}\text { Tersedia } \\
\text { landscape/taman } \\
\text { bandara }\end{array}$ & $\begin{array}{c}3,38 \\
6\end{array}$ & 67,72 & Tinggi/Baik \\
\hline 2 & $\begin{array}{l}\text { Pemanfaatan lahan } \\
\text { bandara }\end{array}$ & $\begin{array}{c}2,14 \\
3\end{array}$ & 42,86 & $\begin{array}{c}\text { Cukup/Cuku } \\
\text { p Baik }\end{array}$ \\
\hline 3 & $\begin{array}{l}\text { Tanaman berbatang } \\
\text { keras dan berdaun } \\
\text { rimbun yang tidak } \\
\text { mengundang } \\
\text { burung (tanaman } \\
\text { tidak berbiji dan } \\
\text { tidak berbuah), atau } \\
\text { tanaman hias }\end{array}$ & $\begin{array}{c}2,16 \\
5\end{array}$ & 43,32 & $\begin{array}{c}\text { Cukup/Cuku } \\
\text { p Baik }\end{array}$ \\
\hline 4 & $\begin{array}{l}\text { Upaya } \\
\text { penghematan energi }\end{array}$ & $\begin{array}{c}2,23 \\
8\end{array}$ & 44,77 & $\begin{array}{c}\text { Cukup/Cuku } \\
\text { p Baik }\end{array}$ \\
\hline 5 & $\begin{array}{l}\text { Pemakaian energi } \\
\text { alternatif seperti } \\
\text { biodiesel, minyak } \\
\text { nabati, energi solar/ } \\
\text { surya }\end{array}$ & $\begin{array}{c}2,54 \\
1\end{array}$ & 50,82 & $\begin{array}{c}\text { Cukup/Cuku } \\
\text { p Baik }\end{array}$ \\
\hline 6 & $\begin{array}{l}\text { Pemakaian Building } \\
\text { Automatic System }\end{array}$ & $\begin{array}{c}2,94 \\
4\end{array}$ & 58,89 & $\begin{array}{c}\text { Cukup/Cuku } \\
\text { p Baik }\end{array}$ \\
\hline 7 & $\begin{array}{l}\text { Bangunan dan } \\
\text { tanaman peredam } \\
\text { kebisingan di } \\
\text { bandara }\end{array}$ & $\begin{array}{c}3,63 \\
3\end{array}$ & 72,67 & Tinggi/Baik \\
\hline 8 & $\begin{array}{l}\text { Penataan taman } \\
\text { bandara }\end{array}$ & $\begin{array}{c}2,07 \\
6 \\
\end{array}$ & 41,53 & $\begin{array}{c}\text { Cukup/Cuku } \\
\text { p Baik }\end{array}$ \\
\hline 9 & $\begin{array}{l}\text { Pengelolaan } \\
\text { kebersihan drainase }\end{array}$ & $\begin{array}{c}2,87 \\
6 \\
\end{array}$ & 57,52 & $\begin{array}{c}\text { Cukup/Cuku } \\
\text { p Baik }\end{array}$ \\
\hline 10 & $\begin{array}{l}\text { Pemeliharaan } \\
\text { saluran } \\
\text { sanitasi/MCK } \\
\end{array}$ & $\begin{array}{c}3,63 \\
3\end{array}$ & 72,66 & Tinggi/Baik \\
\hline 11 & $\begin{array}{l}\text { Tempat } \\
\text { Pembuangan } \\
\text { Sampah Sementara } \\
\text { (TPS) }\end{array}$ & $\begin{array}{c}3,11 \\
5\end{array}$ & 62,31 & Tinggi/Baik \\
\hline 12 & $\begin{array}{l}\text { Tempat } \\
\text { penampungan } \\
\text { khusus limbah B3 }\end{array}$ & $\begin{array}{c}2,94 \\
4\end{array}$ & 58,89 & $\begin{array}{c}\text { Cukup/Cuku } \\
\text { p Baik }\end{array}$ \\
\hline 13 & $\begin{array}{l}\text { Kegiatan bina } \\
\text { lingkungan sekitar } \\
\text { bandara }\end{array}$ & $\begin{array}{c}3,63 \\
2\end{array}$ & 72,66 & Tinggi/Baik \\
\hline 14 & $\begin{array}{l}\text { Jalur alternatif ke } \\
\text { bandara }\end{array}$ & $\begin{array}{c}2,43 \\
7 \\
\end{array}$ & 48,75 & $\begin{array}{c}\text { Cukup/Cuku } \\
\text { p Baik }\end{array}$ \\
\hline 15 & Kegiatan & 2,87 & 57,53 & Cukup/Cuku \\
\hline
\end{tabular}


ISSN 2685-0605

\begin{tabular}{|c|c|c|c|c|}
\hline & $\begin{array}{l}\text { pemantauan } \\
\text { kesehatan } \\
\text { masyarakat sekitar } \\
\text { bandara }\end{array}$ & 6 & & p Baik \\
\hline 16 & $\begin{array}{l}\text { Fasilitas kesehatan } \\
\text { yang disediakan } \\
\text { oleh bandara }\end{array}$ & $\begin{array}{c}3,0 \\
2\end{array}$ & 60,46 & Tinggi/Baik \\
\hline 17 & $\begin{array}{l}\text { Smoking Area yang } \\
\text { di sediakan oleh } \\
\text { bandara }\end{array}$ & $\begin{array}{r}2,7 \\
9\end{array}$ & 54,20 & $\begin{array}{c}\text { Cukup/Cuku } \\
\text { p Baik }\end{array}$ \\
\hline & Rata-rata & & 56,91 & $\begin{array}{c}\text { Cukup/Cuku } \\
\text { p Baik }\end{array}$ \\
\hline \multicolumn{5}{|c|}{$\begin{array}{l}\text { Tabel } 5 \text { Hasil Analisa Deskriptif Persepsi Responden } \\
\text { Pegawai Terhadap Penerapan Konsep Bandara Ramah } \\
\text { Lingkungan Pada Bandara Internasional Sultan } \\
\text { Iskandar Muda }\end{array}$} \\
\hline No & Pernyataan & Mean & Persentase & Keterangan \\
\hline 1 & $\begin{array}{l}\text { Tersedia } \\
\text { landscape/taman } \\
\text { bandara }\end{array}$ & 1,770 & 35,410 & $\begin{array}{c}\text { Rendah/Kurang } \\
\text { Baik }\end{array}$ \\
\hline 2 & $\begin{array}{l}\text { Pemanfaatan } \\
\text { lahan bandara }\end{array}$ & 1,613 & 32,259 & $\begin{array}{c}\text { Rendah/Kurang } \\
\text { Baik }\end{array}$ \\
\hline 3 & $\begin{array}{l}\text { Tanaman } \\
\text { berbatang keras } \\
\text { dan berdaun } \\
\text { rimbun yang } \\
\text { tidak } \\
\text { mengundang } \\
\text { burung } \\
\text { (tanaman tidak } \\
\text { berbiji dan tidak } \\
\text { berbuah),atau } \\
\text { tanaman hias }\end{array}$ & 2,598 & 51,952 & $\begin{array}{c}\text { Cukup/Cukup } \\
\text { Baik }\end{array}$ \\
\hline 4 & $\begin{array}{l}\text { Upaya } \\
\text { penghematan } \\
\text { energi } \\
\end{array}$ & 2,739 & 54,778 & $\begin{array}{c}\text { Cukup/Cukup } \\
\text { Baik }\end{array}$ \\
\hline 5 & $\begin{array}{l}\text { Pemakaian } \\
\text { energi alternatif } \\
\text { seperti } \\
\text { biodiesel, } \\
\text { minyak nabati, } \\
\text { energi solar/ } \\
\text { surya }\end{array}$ & 2,137 & 42,748 & $\begin{array}{c}\text { Cukup/Cukup } \\
\text { Baik }\end{array}$ \\
\hline 6 & $\begin{array}{l}\text { Pemakaian } \\
\text { Building } \\
\text { Automatic } \\
\text { System }\end{array}$ & 3,213 & 64,265 & Tinggi/Baik \\
\hline 7 & $\begin{array}{l}\text { Bangunan dan } \\
\text { tanaman } \\
\text { peredam } \\
\text { kebisingan di } \\
\text { bandara }\end{array}$ & 2,739 & 54,771 & $\begin{array}{c}\text { Cukup/Cukup } \\
\text { Baik }\end{array}$ \\
\hline 8 & $\begin{array}{l}\text { Penataan taman } \\
\text { bandara }\end{array}$ & 3,213 & 64,269 & Tinggi/Baik \\
\hline 9 & $\begin{array}{l}\text { Pemanfaatan } \\
\text { pada air hujan }\end{array}$ & 2,292 & 45,839 & $\begin{array}{c}\text { Cukup/Cukup } \\
\text { Baik }\end{array}$ \\
\hline
\end{tabular}

\begin{tabular}{|c|c|c|c|c|}
\hline 10 & $\begin{array}{l}\text { Bak } \\
\text { penampungan } \\
\text { air (Pond) di } \\
\text { bandara }\end{array}$ & 2,739 & 54,772 & $\begin{array}{c}\text { Cukup/Cukup } \\
\text { Baik }\end{array}$ \\
\hline 11 & $\begin{array}{l}\text { Pengelolaan } \\
\text { kebersihan } \\
\text { drainase }\end{array}$ & 2,925 & 58,490 & $\begin{array}{c}\text { Cukup/Cukup } \\
\text { Baik }\end{array}$ \\
\hline 12 & $\begin{array}{l}\text { Pemeliharaan } \\
\text { saluran } \\
\text { sanitasi/MCK } \\
\end{array}$ & 3,213 & 64,269 & Tinggi/Baik \\
\hline 13 & $\begin{array}{l}\text { Tempat } \\
\text { Pembuangan } \\
\text { Sampah } \\
\text { Sementara } \\
\text { (TPS) }\end{array}$ & 1,562 & 31,248 & $\begin{array}{c}\text { Rendah/Kurang } \\
\text { Baik }\end{array}$ \\
\hline 14 & $\begin{array}{l}\text { Tempat } \\
\text { penampungan } \\
\text { khusus limbah } \\
\text { B3 }\end{array}$ & 2,739 & 54,782 & $\begin{array}{c}\text { Cukup/Cukup } \\
\text { Baik }\end{array}$ \\
\hline 15 & $\begin{array}{l}\text { Jalur alternatif } \\
\text { ke bandara }\end{array}$ & 2,597 & 51,949 & $\begin{array}{c}\text { Cukup/Cukup } \\
\text { Baik } \\
\end{array}$ \\
\hline 16 & $\begin{array}{l}\text { Kegiatan } \\
\text { pemantauan } \\
\text { kesehatan } \\
\text { masyarakat } \\
\text { sekitar bandara } \\
\end{array}$ & 2,481 & 49,614 & $\begin{array}{c}\text { Cukup/Cukup } \\
\text { Baik }\end{array}$ \\
\hline 17 & $\begin{array}{l}\text { Kegiatan bina } \\
\text { lingkungan } \\
\text { sekitar bandara }\end{array}$ & 3,214 & 64,274 & Tinggi/Baik \\
\hline 18 & $\begin{array}{l}\text { Fasilitas } \\
\text { kesehatan yang } \\
\text { disediakan oleh } \\
\text { bandara } \\
\end{array}$ & 2,924 & 58,489 & $\begin{array}{c}\text { Cukup/Cukup } \\
\text { Baik }\end{array}$ \\
\hline 19 & $\begin{array}{l}\text { Smoking Area } \\
\text { yang di } \\
\text { sediakan oleh } \\
\text { bandara }\end{array}$ & 3,214 & 64,272 & Tinggi/Baik \\
\hline 20 & $\begin{array}{l}\text { Transportasi } \\
\text { umum di } \\
\text { bandara }\end{array}$ & 2,924 & 58,489 & $\begin{array}{c}\text { Cukup/Cukup } \\
\text { Baik }\end{array}$ \\
\hline & Rata-rata & & 85 & $\begin{array}{c}\text { Cukup/Cukup } \\
\text { Baik }\end{array}$ \\
\hline
\end{tabular}

\subsection{Pembahasan}

Berdasarkan hasil dari penelitian dan perhitungan sebagaimana yang telah dijabarkan pada sub bab sebelumnya, maka pada sub bab ini akan membahas berdasarkan hasil persepsi dan penerapan konsep bandara ramah lingkungan (eco airport) pada Bandara Internasional Sultan Iskandar Muda sesuai acuan Peraturan Direktur Jenderal Perhubungan Udara Nomor : SKEP/124/VI/2009 Tentang Pedoman Pelaksanaan Bandar Udara Ramah Lingkungan (Eco Airport).

Hasil penelitian dan perhitungan secara keseluruhan nilai rata-rata persepsi responden pengunjung 
bandara terhadap penerapan konsep eco airport pada Bandara Internasional Sultan Iskandar Muda yaitu sebesar $56,91 \%$, yang dikategorikan cukup baik, dan persepsi responden pegawai bandara yaitu sebesar 52,85 \%, yang dikategorikan cukup baik. Nilai terendah persepsi responden pengunjung bandara terhadap penerapan konsep eco airport pada Bandara Internasional Sultan Iskandar Muda terdapat pada penataan taman bandara sebesar 41,53 $\%$ dan dikategorikan dengan kategori cukup baik, nilai terendah persepsi responden pegawai bandara terdapat pada penyediaan Tempat Pembuangan Sampah Sementara (TPS) sebesar $31,25 \%$, sedangkan nilai persepsi tertinggi responden pengunjung bandara terhadap penerapan konsep eco airport pada Bandara Internasional Sultan Iskandar Muda terdapat pada bangunan dan tanaman peredam kebisingan di bandara dengan nilai persentase sebesar $72,67 \%$ yang dikategorikan dengan kategori tinggi/baik, dan nilai tertinggi persepsi responden pegawai bandara terdapat pada pengadaan kegiatan bina lingkungan di sekitar bandara dengan nilai persentase sebesar $64,27 \%$ yang dikategorikan tinggi/baik.

\section{Kesimpulan dan Saran}

\section{$5.1 \quad$ Kesimpulan}

1. Persepsi responden pengunjung bandara terhadap penerapan konsep bandara ramah lingkungan (eco airport) pada Bandara Internasional Sultan Iskandar Muda Provinsi Aceh memiliki nilai ratarata sebesar 56,91 \% yang dikategorikan cukup baik, dengan persentase terbesar yaitu 72,67\% dan persentase terendah sebesar 41,53\%.

2. Persepsi responden pegawai bandara terhadap penerapan konsep bandara ramah lingkungan (eco airport) pada Bandara Internasional Sultan Iskandar Muda Provinsi Aceh memiliki nilai ratarata sebesar 52,85\% yang dikategorikan cukup baik, dengan persentase terbesar yaitu 64,27\% dan persentase terendah sebesar 31,25\%.

\subsection{Saran}

1. Diharapkan penelitian selanjutnya dapat menganalisis tentang penerapan konsep bandara ramah lingkungan (eco airport) sesuai acuan Peraturan Direktur Jenderal Perhubungan Udara Nomor : SKEP/124/VI/2009 Tentang Pedoman Pelaksanaan Bandar Udara Ramah Lingkungan (Eco Airport) di bandara yang sama atau berbeda, sebagai pembanding dengan penelitian sebelumnya.

2. Diharapkan penelitian selanjutnya dapat menganalisis tentang penerapan konsep bandara ramah lingkungan (eco airport) dengan menentukan lebih banyak lagi jumlah respondennya.

\section{Daftar Kepustakaan}

[1] R. M. Rachman, Kajian Manajemen Lingkungan Bandar Udara Ahmad Yani Semarang, Tesis Pascasarjana, Universitas Diponegoro, Semarang, 2007

[2] S. A. Adisasmita, Pengembangan Bandara Berwawasan Eco-Airport, Yogyakarta, 2006

[3] Sevilla, dkk.,Research Methods , Rex Printing Company, Quezon, 1960. City.

[4] Riduwan., Dasar-Dasar Statistika Cetakan Ketiga, Alfabeta, Bandung, 2003.

[5] Sugiyono., Statistika untuk Penelitian Catatan kedua belas, Alfabeta, Bandung, 2007.

[6] Sedarmayanti., Metodologi Penelitian, Refika Aditama, Bandung, 2011

[7] Sugiono., Metode Penelitian Bisnis Edisi I, Alfabeta, Bandung, 2003. 